\title{
LE VERBE EN CREOLE MARTINIQUAIS
}

PAR

\author{
Mme. Elodie Jourdain
}

Autrefois, quand un romancier français plaçait son action aux Antilles il se croyait obligé, pour la couleur locale, de prêter à ses personnages, noirs ou de couleur, un langage spécial caractérisé phonétiquement par l'absence de la consonne $r$ et, du point de vue syntaxique, par l'absence de mots-outils. Ce langage artificiel ne peut plus tromper que les lecteurs ordinaires, les philologues sachant pertinemment qu'il existe dans toutes les anciennes possessions françaises un langage hybride, le créole, qui n'a rien à voir avec le ,,petit nègre” cher aux romanciers. Certains spécialistes du langage ont pu même s'émouvoir à l'idée que les progrès rapides du français dans les pays restés français, ou l'implantation de l'anglais dans les autres, feront disparaître avant longtemps ce parler qui fut le truchement entre des populations de races différentes et qui représente un moment de l'Histoire de France: celui du peuplement d'une grande partie des Antilles, de la Guyane, de la Louisiane et de deux îles de l'Océan Indien: l'île Maurice et la Réunion, ou, pour leur restituer leurs noms de cette époque: l'île de France et Bourbon.

Etant née et ayant vécu de longues années aux Antilles, tant françaises qu'anglaises, nous pouvons résumer, dans une brève étude, l'état de la question telle qu'elle se présente au moins dans le groupe des créoles antillais. Malgré les progrès du français, ce langage est très vivant à la Martinique, à la Guadeloupe, en Guyane française, encore davantage en Haïti (notre ancienne colonie de St. Domingue), où il constitue la langue de $80 \%$ de la population, la langue officielle demeurant le français.

Et malgré 150 ans d'occupation anglaise, le créole français (celui de la Martinique) est également connu de la population de la Dominique, de Ste Lucie, de St. Vincent, de la Grenade et des Grenadines et enfin, cas plus étrange, de la Trinidad. Cette île en 